\title{
Atores e sua capacidade de influência nas políticas setoriais a partir de conferências nacionais
}

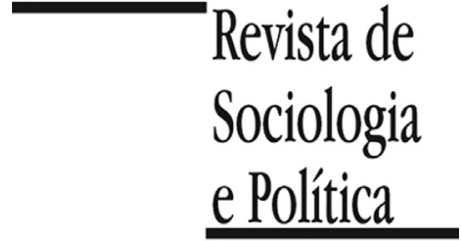

DOI $10.1590 / 1678987318266803$

\section{Viviane Petinelli e Silva ii}

RESUMO Introdução: $\mathrm{O}$ artigo avalia se e em que medida os diferentes atores presentes em conferências de políticas públicas influenciam o resultado final do processo decisório, expresso nas propostas nele aprovadas e incorporadas aos programas da respectiva política setorial. Supõe-se que (1) a dinâmica de interação entre atores governamentais e não-governamentais, bem como (2) a dinâmica de atores não-governamentais entre si, impactam a capacidade de influência de cada ator na respectiva política. Busca-se verificar (1) se uma dinâmica mais cooperativa favoreceria a reprodução da capacidade de influência daqueles atores, enquanto (2) uma interação mais competitiva tenderia a gerar uma capacidade de influência distinta da alcançada na conferência e mais equilibrada na política setorial. Materiais e Métodos: Examinamos a capacidade de influência dos atores a partir das propostas de seu interesse aprovadas em seis conferências de políticas públicas: a Conferência de Aquicultura e Pesca, a de Cidades, a de Meio Ambiente, a Conferência de Esporte, a de Políticas para Mulheres e a de Políticas de Promoção da Igualdade Racial. O trabalho compara o conteúdo das propostas aprovadas com o conteúdo dos programas da política setorial dos anos seguintes. Por conteúdo, entende-se o objetivo, a finalidade, a intenção expressa na proposta, não da redação ipsis litteris do texto em si mesmo. Por meio de palavras-chave identificadas em cada proposta, elas foram classificadas (1) em incorporadas ou rejeitadas aos programas governamentais ou (2) segundo o ator interessado. Para tanto, utilizou-se o caderno final de propostas de cada conferência, bem como os planos de ação que descreviam os programas de cada política nos anos subsequentes. Resultados: Dessa análise se obteve a capacidade de influência de cada ator na política setorial a partir das propostas de seu interesse aprovadas em conferências. Os resultados mostram que a capacidade de influência de cada ator na política varia e é afetada pela dinâmica política da área em que atua, como esperado. Discussão: Embora sejam espaços potencialmente inclusivos, as conferências podem gerar resultados pouco representativos dos atores nela presentes, em decorrência da forma se combinam seu desenho e a dinâmica política da área em que é realizada.

PALAVRAS-CHAVE: conferências; propostas; atores; influência; políticas públicas.

Recebido em 15 de Agosto de 2017. Aceito em 19 de Março de 2018.

\section{Introdução ${ }^{1}$}

${ }^{1}$ Este artigo apresenta resultados de uma pesquisa desenvolvida com o apoio do Conselho Nacional de Desenvolvimento Científico e Tecnológico - $\mathrm{CNPq}$ - ao qual se destina especial agradecimento. Também agradece-se as ricas contribuições e sugestões dos parecistas da Revista de Sociologia e Política, incorporadas na revisão final desse trabalho.
A s políticas públicas consistem na principal expressão da inação e da ação do Estado em uma sociedade (Bachrach \& Baratz 1962; Dye 1984). Por meio delas, o Estado se exime, interfere, regula, promove, fortalece, reduz, elimina velhos e cria novos contextos socioeconômicos. Tais resultados dependem das conexões entre os diversos atores governamentais e não-governamentais em diferentes ambientes institucionais e para além dos limites organizacionais. Em cada área de política, estas interações envolvem diferentes interesses, conflitos, ideias e discursos (Marques 2013, pp.1-2), os quais são disputados em uma série de momentos, para alguns concomitantes, para outros, sequenciais, englobando desde a escolha dos problemas sociais a serem enfrentados, passando pela definição das soluções mais adequadas, até a avaliação dos resultados das políticas implementadas.

Nessa disputa, a capacidade de influência dos atores não-governamentais na política é afetada pela dinâmica política da área em que atuam, isto é, pelo tipo de rede de atores e seu padrão de interação. Cada política caracteriza-se por um tipo de rede: umas compreendem um número reduzido de atores, enquanto outras abrangem ampla diversidade de grupos. Certas políticas envolvem, 
${ }^{2}$ Como mostra Lavalle e Szwako (2015), o processo de políticas públicas no Brasil sempre foi permeado por interações socioestatais, caracterizadas tanto pela autonomia dos atores societais, quanto pela interdependência deles com o Estado. Em certos contextos, práticas autônomas foram mais promovidas pelos atores societais, enquanto, em outros, interações sistemáticas entre Estado e sociedade ocorreram mais intensamente. sobretudo, atores de mercado, empresários e trabalhadores, agrupados em entidades patronais, ao passo que outras abrigam quase exclusivamente grupos e movimentos sociais, como nas políticas de minorias. Nas áreas em que prevalecem os atores de mercado, a configuração política tende a ser mais corporativa, enquanto, nas políticas setoriais em que convivem atores de mercado e sociais ou apenas atores sociais, a configuração tende a ser mais pluralista. Dependendo do tipo de rede, padrões de interação distintos consolidam-se. Redes mais corporativas tendem a cristalizar relações cooperativas entre os atores societais e entre estes e os atores governamentais. Redes pluralistas, por sua vez, geram padrões de interação tanto colaborativos como competitivos. Diferentes tipos de rede e de relação política entre os atores dão origem a distintas dinâmicas políticas e, por conseguinte, a variadas capacidades de influência dos atores na respectiva política.

Até aproximadamente a década de 1980, o processo de políticas públicas no Brasil envolvia atores governamentais - legisladores, governantes e gestores - $\mathrm{e}$ um número limitado de atores não-governamentais - da sociedade civil, de mercado e a mídia, os quais interagiam por canais formais e informais de negociação e barganha política ${ }^{2}$. Com a redemocratização do país e a promulgação da Constituição Federal de 1988 (doravante CF/88), teve início um processo de democratização da gestão pública tanto pela criação, disseminação e institucionalização de uma estrutura participativa no âmbito de diversas políticas públicas e casas legislativas nas três esferas da federação, quanto pela distribuição de cargos governamentais para ativistas societais e líderes sindicais e de movimentos sociais (Lavalle \& Szwako 2015; Abers, Serafim \& Tatagiba 2014). Em decorrência disto, a interdependência dos atores societais com o Estado foi progressivamente se intensificando e sua autonomia frente ao Estado, reduzindo-se.

No nível nacional, esse processo alcançou seu ápice na primeira década do século XXI, nos dois governos Lula (2003-2010). Em oito anos, esse governo criou 9 conselhos nacionais e renovou e ampliou o poder decisório de outros 7 , bem como realizou 72 conferências sobre 35 políticas setoriais distintas (Petinelli 2014). Ademais, diversos cargos de alto escalão no governo foram concedidos para líderes sindicais: na primeira gestão Lula, $43 \%$ e, na segunda, $45 \%$ dos ministros mantinham relações próximas aos movimentos sociais (D'Araújo 2009).

Em resposta a esse movimento de democratização da gestão pública, surgiram diversas investigações preocupadas em compreender e explicar a importância e os resultados produzidos pelas instituições participativas (doravante IPs), criadas e promovidas em contextos políticos distintos. Num primeiro momento, ao longo dos anos 1990, as análises buscaram consolidar as IPs como objetos científicos legítimos, que serviam para o alcance de determinados objetivos político-normativos subjacentes ao processo de democratização brasileiro, como a promoção de inclusão política. A partir de meados de 2000, tornou-se claro os limites das IPs em alcançar tais objetivos e, por essa razão, uma nova geração de investigações emergiu para apontar seus limites (Romão \& Martelli 2013).

Tendo superado a defesa e a crítica às IPs, a atual geração de estudos tem se preocupado em apontar e examinar os desenhos e resultados produzidos pelas mesmas em diferentes políticas setoriais, em termos da qualidade da representação e deliberação e do impacto de suas decisões nas políticas públicas. Essas investigações mostram, grosso modo, que as conferências têm assegurado ampla participação dos cidadãos e apresentado fortes elementos deliberativos (Almeida 2013; Avritzer 2013; Cunha 2013; Faria \& Lins 2013; Pogrebinschi 2013; Ramos \& Faria 2013), assim como têm influenciado as decisões 
do Poder Executivo Federal e as proposições de lei do Congresso Nacional (Petinelli 2013; 2014; 2015; Pogrebinschi \& Santos 2011).

Por outro lado, esses estudos apontam para uma variação expressiva nos resultados de conferências de políticas setoriais distintas. Petinelli (2014) atribui as diferenças na capacidade de influência das conferências a três aspectos: 1) o desenho institucional da conferência; 2) o arcabouço institucional-legal da política setorial; 3) a dinâmica de interação entre os atores governamentais e não-governamentais. Em áreas de política menos institucionalizadas, a influência das propostas aprovadas em conferência na respectiva política setorial seria mais expressiva, enquanto, nas políticas mais institucionalizadas, a capacidade de influência variaria segundo o desenho da conferência e a dinâmica política da área.c

Ao determinar quem, em que proporção e como participa, o desenho incluiria, em menor ou maior medida, os atores não-governamentais envolvidos na política setorial e possibilitaria sua influência, em menor ou maior grau, nas propostas aprovadas ao longo do processo conferencista. Segundo Petinelli (2017), em havendo regras claras de seleção e composição de delegados e uma dinâmica deliberativa que reforça o cenário representativo criado, a capacidade de influência dos atores tende a corresponder à proporção em que são representados no processo conferencista. $\mathrm{Na}$ ausência de regras de representação e deliberação, por outro lado, tal capacidade de influência tende a refletir o nível de influência política dos mesmos, o qual é constrangido pela dinâmica política na área em discussão.

Dada a capacidade de influência das conferências nas políticas setoriais e nas proposições legislativas e os efeitos do desenho institucional e da dinâmica política na capacidade de os atores influenciarem o resultado final do processo conferencista, isto é, o caderno de propostas aprovado, este artigo lança luz sobre a capacidade de influência dos diferentes atores na política setorial a partir das propostas de seu interesse, aprovadas em conferências. Avalia-se se e em que medida tais propostas são incluídas nos programas da respectiva política nos anos seguintes ao da conferência.

Uma vez que, em cada política, a produção de políticas públicas é disputada por atores distintos com um padrão de interação próprio, supõe-se que essa dinâmica, entre os atores societais e governamentais, impacte a capacidade de influência de cada segmento na respectiva política, inclusive quanto às propostas de seu interesse aprovadas em conferências.

Nesse sentido, testamos a hipótese de que uma dinâmica política caracterizada por redes de atores menos numerosas, de padrão de interação cooperativo, favoreceria a reprodução da capacidade de influência dos atores na conferência e na própria política. Por outro lado, uma dinâmica política caracterizada por uma rede ampla e diversificada de atores, de relações predominantemente conflituosas, geraria mais custos de mediação, negociação e coordenação dos diferentes interesses dos atores, o que afetaria negativamente a capacidade de influência dos mesmos a partir de conferências no processo de políticas.

Para testar tais suposições, o trabalho examina a capacidade de influência dos atores na política setorial a partir das propostas de seu interesse aprovadas em seis conferências de políticas públicas: a $1^{\text {a }}$ Conferência de Aquicultura e Pesca (doravante $1^{\mathrm{a}}$ CAP), $1^{\mathrm{a}}$ de Cidades ( $1^{\mathrm{a}}$ Concidades), a $1^{\mathrm{a}}$ de Meio Ambiente ( $\left.1^{\mathrm{a}} \mathrm{CMA}\right)$, a $1^{\mathrm{a}}$ Conferência de Esporte (doravante $1^{\mathrm{a}} \mathrm{CE}$ ), a $1^{\mathrm{a}} \mathrm{de}$ Políticas para Mulheres $\left(1^{\mathrm{a}} \mathrm{CPM}\right)$ e a $1^{\mathrm{a}}$ Conferência de Políticas de Promoção da Igualdade Racial ( $1^{\text {a }}$ CPIR). Todas foram realizadas no primeiro mandato de Lula (2003-2006), de forma inédita, tendo sido organizadas por atores governa- 
mentais e não-governamentais conjuntamente e ministérios liderados por políticos da base aliada e de partidos de esquerda. Por um lado, a análise dessas seis conferências permitiu variações na dinâmica política e, assim, comparações quanto à capacidade de influência dos atores na política. Por outro, ela possibilitou o controle dos efeitos de condicionantes contextuais, tais como vontade política, sobre os resultados encontrados.

A capacidade de influência dos atores foi aferida por meio de três análises. Primeiro, comparou-se o conteúdo das propostas aprovadas com o conteúdo dos programas da política setorial dos anos seguintes ao da conferência, classificando-as como aprovadas ou rejeitadas. Em seguida, classificou-se cada proposta, segundo ator de interesse, de modo a obter a capacidade de influência de cada grupo na política setorial, a partir das propostas aprovadas em conferências. Nessa classificação, considerou-se somente o ator interessado pela recomendação aprovada, não sendo considerado, nem analisado, se ele foi ou não responsável por sua formulação. Por fim, confrontou-se a capacidade de influência de cada ator no caderno final de propostas aprovado em conferência (Petinelli 2017) com sua capacidade de influência na política setorial.

O trabalho está dividido em três seções, além desta introdução. Na próxima seção, mapeia-se as principais contribuições da literatura sobre os efeitos da dinâmica política no processo de políticas públicas e se apresenta nossas hipóteses a esse respeito. Em seguida, descreve-se a dinâmica política das seis políticas setoriais examinadas e seus efeitos esperados sobre a capacidade dos atores de influenciar, por meio das propostas de seu interesse aprovadas na conferência, os programas da respectiva política. Na última seção, apresenta-se a metodologia e os resultados obtidos acerca da capacidade de influência dos diferentes grupos nos programas da respectiva política. Examina-se a relação entre dinâmica política e capacidade de influência dos diferentes atores nãogovernamentais de cada política e se compara tais resultados à capacidade de influência desses atores no resultado final da conferência.

Por investigar uma conferência de cada setor, realizada no primeiro governo Lula (2003-2006), os resultados não podem ser generalizados para o conjunto das conferências do setor, aplicando-se exclusivamente ao escopo de análise desse trabalho. Para tanto, seria necessária uma análise longitudinal dos resultados das conferências em cada setor, o que não constitui objetivo dessa primeira investigação.

\section{Dinâmica política e capacidade de influência de atores não-governamentais: reflexões e hipóteses}

Uma das implicações da progressiva democratização do processo de políticas públicas no Brasil pós-1985 consiste na possibilidade, cada vez maior, de influência de atores não-governamentais nas decisões tomadas. Tal oportunidade não só tem se concretizado pela concessão de cargos para ativistas e líderes societais e pela criação e promoção de experiências participativas, como também tem sido aproveitada pela pressão, por meio de protestos e de canais informais de interlocução com atores governamentais (Abers, Serafim \& Tatagiba 2014).

A capacidade de influência dos atores não-governamentais decorre, entre outros, do conhecimento que eles possuem e da posição política que ocupam como fontes de apoio e de representação política. Esses atores apresentam expertise para elaborar e executar políticas, detêm conhecimento sobre as causas e os efeitos dos problemas sociais e promovem a difusão de novas ideias e padrões de comportamento. Em contextos de incerteza e informação assimétrica, esses grupos ajudam os governos a identificar as necessidades sociais, a enquadrar as questões para debate coletivo, a propor políticas específicas para 
cada problema e a identificar os aspectos mais importantes para negociação de cada resposta política (Haas 1992).

Além de possuírem conhecimento e expertise, os atores não-governamentais constituem fontes de apoio político e objetos de representação política por parte dos atores governamentais em regimes democráticos. Tal condição possibilita que esses atores participem, legitimamente, de um processo de debate permanente, ao lado dos partidos políticos e do governo. Este processo se desenrola em um "sistema de arenas públicas", no qual imagens das políticas são formadas e se tornam dominantes, atividades reivindicatórias por parte de grupos sociais organizados acontecem e encontram resultados, problemas são definidos, soluções são propostas e políticas surgem (Fischer 2003).

A capacidade de influência dos atores não-governamentais envolvidos em cada política está condicionada, porém, à configuração político-institucional da área. Cada política constitui uma área de intervenção governamental distinta, com arcabouço institucional específico. Cada desenho institucional dá origem a uma rede de atores de interesse diferente, com composição, funções, padrão de interação e distribuição de poder, e regras de conduta específicos. Das variadas combinações desses fatores, dinâmicas políticas próprias emergem e se consolidam, ao longo do tempo, nas diversas políticas setoriais.

A dinâmica política pode se caracterizar por redes formadas ora por um amplo conjunto de atores não-governamentais ora por um número reduzido deles, em cada área de política. Imbuídos de interesses e demandas particulares, esses atores representam organizações da sociedade civil ou de mercado com capacidades, estratégias, grau de profissionalização, recursos e desempenhos distintos.

Ao se agrupar, esses atores dão origem a redes com funções específicas. Certas redes funcionam como canais de acesso dos grupos aos processos de tomada de decisão pública. Outras possibilitam a troca de informações e a consulta mútua entre atores governamentais e não-governamentais. Algumas redes se formam para lidar com problemas de negociação e de coordenação dos atores nos processos, enquanto outras destinam-se à cooperação e ao compartilhamento das competências de elaboração e implementação de políticas.

A função assumida reflete, em boa medida, o tipo de relação entre os atores governamentais e não-governamentais em cada área de política. Algumas redes envolvem participação voluntária, enquanto, em outras, a adesão é compulsória. Certas redes são ordenadas, outras são caóticas. Algumas redes investem mais pesadamente em ações por dentro das instituições do Estado e buscam ocupar posições na burocracia e em arenas participativas. Já outras apostam em repertórios fora do Estado e se utilizam mais de protestos e ações diretas de pressão na relação com o Estado (Abers, Serafim \& Tatagiba 2014).

As diferentes redes também desenvolvem relações de poder distintas. Redes de coordenação, por exemplo, baseiam-se no conflito e na competição entre os grupos. Nelas, os acordos alcançados requerem negociação e barganha. Por outro lado, redes de cooperação fundam-se em relações colaborativas e na atuação conjunta e compartilhada entre atores estatais e não estatais. Nelas, há busca por consenso por meio de consulta aos participantes.

Dependendo do tipo de relação de poder estabelecida, os atores adotam regras de conduta próprias, caracterizadas ou por convenções de interação ou por regras do jogo político. Quando as relações são predominantemente conflituosas, as negociações entre os interesses competitivos levam à definição de regras claras para o jogo político, de modo a viabilizar as decisões, sobretudo via negociações e barganhas políticas. Por sua vez, relações cooperativas possibilitam a adoção de convenções para balizar e garantir legitimidade às 
ações dos atores governamentais e não-governamentais nos processos de políticas.

Tais padrões de interação e de conduta decorrem, notadamente, do tipo de distribuição de poder entre os atores políticos e societais em cada área. Em certas políticas, o poder está mais concentrado nas mãos dos atores não-governamentais, que capturam ou colonizam as instituições públicas. Em outras, o Estado tende a dominar e instrumentalizar os interesses privados segundo sua vontade. Certas políticas, por sua vez, apresentam uma distribuição de poder relativamente equilibrada, as quais se refletem ou em uma atuação independente dos atores governamentais e não-governamentais, ou em relações intensas entre os mesmos.

No âmbito de cada subsistema de política, esses atributos se misturam e dão origem a dinâmicas políticas singulares. Redes menos e mais numerosas são formadas e reproduzem diferentes repertórios de interação Estado-sociedade. Dessa combinação, decorrem pelo menos cinco tipos de dinâmicas políticas: a clientelista (Waarden 1992), a corporativista e a pluralista (Schmitter 1974), e as redes temáticas, em contraposição aos triângulos de ferro (Heclo 2015).

Grosso modo, a estrutura clientelista e os triângulos de ferro são formados por apenas um ou dois grupos de interesse, os quais detêm e exercem o poder político no Estado. Nesses tipos de rede, as relações entre os atores governamentais e não-governamentais são horizontais, baseadas na cooperação e na consulta nos processos decisórios.

Uma configuração oposta se observa nas redes temáticas. Estas são compostas por muitos atores governamentais e não-governamentais, interessados em um mesmo tema, os quais apresentam acesso livre e interação flutuante. Nelas, o poder político é distribuído entre os diversos atores, o que gera relações predominantemente competitivas e conflituosos entre os mesmos (Rhodes 2006).

Entre os dois extremos, encontram-se as dinâmicas mais corporativistas e pluralistas, cuja composição e padrões de relação e de distribuição de poder se aproximam da configuração clientelista e das redes temáticas, respectivamente. A dinâmica corporativista se caracteriza pelo baixo número e baixa diversidade de atores envolvidos, ao passo que as redes pluralistas são compostas por um amplo e variado conjunto de atores não-governamentais. Os poucos grupos não-governamentais no bojo da dinâmica corporativista estão organizados em um sistema de intermediação de interesses, no qual os atores governamentais trocam privilégios de acesso e recursos econômicos por cooperação e apoio político por parte dos atores não-governamentais (Schmitter 1974). No pluralismo, por outro lado, as diversas organizações encontram-se espalhadas e disputam espaço e influência no processo de políticas de modo competitivo, ora mais cooperativo, ora mais conflituoso (Waarden 1992).

Dependendo da dinâmica política, o processo e o conteúdo das políticas sofre mais ou menos constrangimentos, como resultado, notadamente, do grau de dispersão do poder e dos custos de coordenação gerados pelo tipo de rede. Nas políticas setoriais que abrigam poucos grupos de interesse, atuantes de modo cooperativo (padrão clientelista/corporativista), o poder é mais concentrado e os custos de coordenação menores, o que tende a favorecer a capacidade de influência de cada ator na respectiva política.

Já nas políticas setoriais cujo conjunto de atores é plural e o padrão de interação entre eles é competitivo (padrão das redes temáticas e pluralistas), a capacidade de influência dos atores tende a ser menor, dada a maior dispersão do poder e os maiores custos de coordenação dos variados interesses em disputa. Dentre estes extremos estão as políticas setoriais com dinâmicas 
competitivas, mas de modo colaborativo, nos qual há menores custos de coordenação, a despeito da expressiva dispersão de poder.

Disso se supõe que, nas políticas setoriais com dinâmica política mais clientelista ou corporativista, a capacidade de influência de cada ator na respectiva política, via propostas aprovadas na conferência, tende a se refletir, em grande medida, nos resultados da conferência. Organizados em um sistema de intermediação de interesses, as relações de cooperação entre os atores governamentais e não-governamentais, e entre os próprios atores não-governamentais, legitimariam os resultados acordados em conferência, o que levaria à reprodução da capacidade de influência de cada ator alcançada na conferência na política setorial.

Por outro lado, nas políticas setoriais com dinâmica mais plural e conflituosa, a capacidade de influência de cada grupo na respectiva política tende a ser mais equilibrada. A dispersão de poder e a disputa por influência no processo de políticas torná-lo-iam mais competitivo e, como desdobramento, a capacidade de influência de cada ator alcançada na conferência não necessariamente se traduziria em influência na política setorial.

Por fim, nas políticas setoriais com dinâmicas competitivas, mas colaborativas, a capacidade de influência de cada ator na respectiva política, via propostas aprovadas na conferência, tende a refletir a distribuição de poder entre os mesmos. Não obstante a dispersão de poder, as relações de cooperação entre os atores não-governamentais e entre esses e os atores governamentais possibilitariam que as propostas dos atores não-governamentais politicamente mais influentes na área fossem as mais incorporadas após a conferência.

A seguir, descreve-se a dinâmica política nas políticas de aquicultura e pesca, urbana, de meio ambiente, esporte, nas políticas para mulheres e de promoção da igualdade racial, bem como se apresentam os efeitos esperados de cada dinâmica sobre a capacidade de influência dos atores.

III. Dinâmica política na política de aquicultura e pesca, urbana, de meio ambiente, de esporte, nas políticas para mulheres e de promoção da igualdade racial e seus efeitos esperados sobre a capacidade de influência dos atores

A dinâmica política que caracteriza a política de aquicultura e pesca, urbana, de meio ambiente, de esporte, as políticas para mulheres e de promoção da igualdade racial constitui um produto histórico do processo de construção institucional de cada política pública. A forma como Estado e sociedade relacionaram-se em cada área de política, em certos momentos de forma mais autônoma, em outros, de modo interdependente, deu origem a tipos particulares de rede de atores com padrão próprio de interação com o Estado.

A construção da política de Aquicultura e Pesca e da Política Urbana teve início na década de 1950 e 1960, respectivamente, na criação da Divisão de Caça e Pesca e da Caixa de Crédito da Pesca, sob o Ministério da Agricultura e do Serviço Federal de Habitação e Urbanismo (SERFHAU). Duas décadas antes, ganhara a agenda governamental a temática ambiental e a de esportes. A primeira integrou o projeto de industrialização nacional, promovido por Vargas (1937-1945), o qual exigia a presença ativa do Estado como planejador, produtor de insumos e fornecedor de infraestrutura básica para a indústria nascente. Já a política de desporto surgiu da necessidade de intervenção governamental na disputa política entre duas associações civis: a pró-profissionalização do esporte e a pró-amadorismo. Em resposta, Vargas criou a Divisão de Educação Física (DEF) em 1937, na estrutura do Ministério da Educação e Cultura, para formular e gerir a política nacional de esportes, voltada para o esporte de alto rendimento nas escolas, notoriamente o futebol (Petinelli 2014). 
${ }^{3} \mathrm{O}$ movimento feminista brasileiro se formou no final do século XIX, com o objetivo de lutar pelo direito de sufrágio para as mulheres no país. A conquista do sufrágio em 1932 foi acompanhada, porém, por um refluxo na atuação desse movimento, o qual perdurou até o início dos anos 70 .

${ }^{4}$ Dentre as organizações civis que formavam o Movimento

Negro Unificado, estavam: a Coordenação Nacional de

Entidades Negras; a Coordenação Nacional de Quilombos; a União de Negros pela Igualdade; a Articulação de Organizações de Mulheres Negras; o Fórum Nacional de Mulheres Negras; e o Fórum Nacional de Juventude Negra (Ribeiro 2009).

5 Para uma exposição detalhada, ver Petinelli (2014)
A construção institucional dessas políticas foi acompanhada pela formação gradual de uma rede de atores não-governamentais, com composição e padrão de interação específicos. No período de 1930 a 1970, a formulação da política de pesca, da política urbana, de meio ambiente e de esporte foi orientada pelo nacional-desenvolvimentismo, o que possibilitou e estimulou a formação de uma comunidade empresarial bem-articulada e politicamente influente nas quatro áreas. A legislação e os programas governamentais no período privilegiavam, notoriamente, a dimensão econômica de tais políticas e, por conseguinte, os atores de mercado. Nesse contexto, os demais atores não-governamentais envolvidos em alguma medida com esses tópicos, como as colônias de pescadores artesanais e os profissionais liberais, foram desconsiderados no processo de políticas.

Tal configuração político-institucional das políticas de aquicultura e pesca, urbana, de meio ambiente e de esporte sofreu um primeiro abalo nos anos 1970 e no início na década de 1980, em um contexto de expressiva efervescência social pela redemocratização do país. Com o auxílio de uma ala progressista da Igreja Católica, os pescadores artesanais se organizaram em sindicatos, associações civis e movimentos para representá-los junto ao Estado. Na política urbana e de meio ambiente, emergiram e rapidamente ganharam força movimentos sociais, respectivamente, os movimentos urbanos e os movimentos ambientalistas, com uma postura crítica à orientação política vigente. $\mathrm{Na}$ área de desporto, o fomento contínuo à formação de educadores físicos nas décadas anteriores, por meio de planos e campanhas para o desenvolvimento da educação física, culminou na formação de uma comunidade de esporte educativo e participativo, focada em lazer, crítica à orientação unilateral do esporte para o alto rendimento.

Concomitantemente, os anos 1970 e 1980 assistiram o ativismo de movimentos feministas e negros e a formulação das primeiras políticas para mulheres e de promoção da igualdade racial. Após quatro décadas de inação ${ }^{3}$, o movimento feminista renasceu a partir de um conjunto diversificado de grupos e de mulheres, entre elas, intelectuais, anarquistas e líderes operárias, com duas bandeiras políticas principais: uma de oposição à ditadura militar e outra de resistência ao poder e à dominação do homem sobre a mulher. Na mesma época, surgiu o Movimento Negro Unificado, composto por um amplo conjunto de organizações civis ${ }^{4}$, com um objetivo comum: lutar contra o racismo e contra a exclusão política e socioeconômica da população negra. Pela pressão dos movimentos feminista e negro, as primeiras políticas para mulheres e de promoção da igualdade racial foram instituídas nos anos 1980, além de terem sido incluídas, de forma inédita, nas temáticas de gênero e racial na CF/88 (Petinelli 2014).

Na década de 1990, em um contexto de descentralização e de democratização do processo de geração de políticas públicas, os diferentes atores não-governamentais presentes na política de aquicultura e pesca, urbana, de meio ambiente, de esporte, nas políticas para mulheres e de promoção da igualdade racial se consolidaram como influenciadores e veto players. Ademais, novos grupos surgiram por um processo de especialização temática e diferenciação organizacional, notadamente no âmbito da política ambiental e das políticas para mulheres e de promoção da igualdade racial ${ }^{5}$.

Na política de aquicultura e pesca, a forte insatisfação dos pescadores artesanais e dos empresários com a política pesqueira do Ibama e do Ministério do Meio Ambiente (MMA) de 1989 a 1998, levou-os a se aproximarem e colaborarem para alcançar as conquistas políticas almejadas, dentre elas a transferência das funções de desenvolvimento e fomento da pesca para o Ministério da Agricultura e Abastecimento (Boszczowski \& Borghetti 2006). 
Na política urbana e ambiental, as vitórias constitucionais dos movimentos urbanos e ambientalistas - instituição do princípio da função social da propriedade e da obrigatoriedade de elaboração de um Plano Diretor Municipal para municípios com mais de 20 mil habitantes (Bassul 2002) e reconhecimento do meio ambiente como patrimônio público e direito de todos (Vieira \& Cader 2007) - possibilitaram-lhes lutar por legislações e políticas governamentais de seu interesse, combatendo-se as demandas de interesse e ações governamentais em benefício exclusivo do setor empresarial. Os primeiros saíram vitoriosos do processo de elaboração e aprovação do Estatuto da Cidade em 2001 (Lei n $^{\circ}$ 10.257), enquanto os movimentos ambientalistas lograram êxito na criação do MMA e na aprovação da Lei das Águas em 1997, da Lei de Crimes Ambientais $\left(\right.$ Lei $^{\circ}$ 9.605/98) e da Lei $n^{\circ} 9.985$ de 2000, que instituiu o Sistema Nacional de Unidade de Conservação da Natureza (SNUC).

Na política de esporte, a comunidade de esporte educativo e a de esporte participativo conseguiram, de forma inédita, a inclusão, pelo art. 217 da CF/88, do dever do Estado de fomentar práticas desportivas formais e não formais, como direito de todos, e o dever de destinar recursos públicos para a promoção prioritária do desporto educacional. Além disso, a pressão dessas comunidades possibilitou, pela Lei Maguito Viola (Lei n 9.981 de 14 jul. 2000), a inclusão de representantes desses dois segmentos na mais alta instância de participação junto ao governo federal, à época, o Conselho de Desenvolvimento do Desporto Brasileiro (Bueno 2008).

Por fim, no que concerne às políticas para mulheres e de promoção da igualdade racial, pouco se avançou ao longo da década de 1990. A iniciativa mais expressiva foi o programa "Brasil Gênero e Raça", criado nos anos 2000, no âmbito do Ministério do Trabalho e Emprego, para identificar e combater as práticas discriminatórias nas relações de trabalho (Yannoulas \& Soares 2009). A pouca atenção dada a essas temáticas, sobretudo pelo governo federal, estimulou os diferentes movimentos e entidades com atuação nessas áreas feministas, negros e indígenas - a atuarem de modo cooperativo, para pressionar o governo por políticas mais sistemáticas e abrangentes.

Desse modo, na virada do século, a dinâmica política na política de aquicultura e pesca, urbana, de meio ambiente, de esporte, das políticas para mulheres e de promoção da igualdade racial já apresentava contornos bem delineados. Como se observa no Quadro 1, a rede de atores na política de aquicultura e pesca era composta basicamente por pescadores, aquicultores e empresários. O padrão de interação era cooperativo, aproximando-se do tipo corporativista. Nas demais, a rede de atores era mais numerosa, diversificada e suas relações eram mais competitivas, como observado nas redes pluralistas. Contudo, se nas políticas urbana, de meio ambiente e de esportes a interação entre os atores não-governamentais mostrava-se conflituosa, nas políticas para mulheres e de promoção da igualdade racial a relação era mais colaborativa.

Da combinação do tipo de rede e do padrão de interação dos atores com o Estado resultam dinâmicas políticas distintas, ora mais corporativistas, ora mais pluralistas. Isso, por sua vez, afeta distintamente a capacidade de influência dos atores sobre o processo de políticas. Por hipótese, dinâmicas corporativistas favorecem a capacidade de influência dos atores, ao passo que dinâmicas pluralistas podem tanto potencializar como limitar tal capacidade. As dinâmicas conflituosas tendem a reduzir e melhor distribuir a capacidade de influência, enquanto as interações competitivas, mas cooperativas, tendem a favorecê-la por não impactar o poder político que os atores apresentam na área de política.

Disso se espera que, na política de aquicultura e pesca, a capacidade de influência de cada ator no resultado final da conferência se reflita na respectiva política. Já na política urbana, de meio ambiente e de esporte, a capacidade de 
Quadro 1 - Principais atores não-governamentais e padrão de interação na Política de Aquicultura e Pesca, Urbana, de Meio Ambiente, de Esporte, nas Políticas para Mulheres e de Promoção da Igualdade Racial nos anos 2000

\begin{tabular}{|c|c|c|}
\hline Política & $\begin{array}{l}\text { Principais atores } \\
\text { não-governamentais }\end{array}$ & Padrão de interação \\
\hline \multirow[t]{3}{*}{ Aquicultura e Pesca } & $\begin{array}{l}\text { Pescadores artesanais e aqui- } \\
\text { cultores familiares }\end{array}$ & \\
\hline & Empresários & \\
\hline & Entidades civis & Cooperativo \\
\hline \multirow[t]{3}{*}{ Urbana } & Movimentos urbanos & \\
\hline & Empresários & \\
\hline & Operadores/concessionários & Competitivo e adversarial \\
\hline \multirow[t]{3}{*}{ Meio Ambiente } & Movimentos ambientalistas & \\
\hline & Entidades civis & \\
\hline & Empresários & Competitivo e adversarial \\
\hline \multirow[t]{3}{*}{ Esporte } & $\begin{array}{l}\text { Comunidade do esporte } \\
\text { profissional }\end{array}$ & \\
\hline & $\begin{array}{l}\text { Comunidade do esporte } \\
\text { educativo }\end{array}$ & \\
\hline & $\begin{array}{l}\text { Comunidade do esporte } \\
\text { participativo }\end{array}$ & Competitivo e adversarial \\
\hline \multirow[t]{2}{*}{ Para Mulheres } & Movimentos feministas & \\
\hline & Entidades civis & $\begin{array}{c}\text { Competitivo mas } \\
\text { colaborativo }\end{array}$ \\
\hline \multirow{3}{*}{$\begin{array}{l}\text { Promoção da Igualdade } \\
\text { Racial }\end{array}$} & Movimentos quilombolas & \\
\hline & Movimentos indígenas & \\
\hline & Entidades civis & $\begin{array}{l}\text { Competitivo, mas } \\
\text { colaborativo }\end{array}$ \\
\hline
\end{tabular}

Fonte: A autora.

Quadro 2 - Dinâmica política e seus efeitos esperados sobre a capacidade de influência dos atores não-governamentais na Política de Aquicultura e Pesca, Urbana, de Meio Ambiente, de Esporte, nas Políticas para Mulheres e de Promoção da Igualdade Racial

\begin{tabular}{|c|c|c|}
\hline Política & Dinâmica Política & $\begin{array}{l}\text { Capacidade de influência dos } \\
\text { atores }\end{array}$ \\
\hline Aquicultura e Pesca & Corporativista & $\begin{array}{l}\text { Muito próxima à capacidade al- } \\
\text { cançada na } 1^{\mathrm{a}} \mathrm{CAP}\end{array}$ \\
\hline Urbana & Pluralista & $\begin{array}{l}\text { Distinta e mais equilibrada que a } \\
\text { alcançada na } 1^{\text {a }} \text { Concidades }\end{array}$ \\
\hline Meio Ambiente & Pluralista & $\begin{array}{l}\text { Distinta e mais equilibrada que a } \\
\text { alcançada na } 1^{\text {a }} \mathrm{CMA}\end{array}$ \\
\hline Esporte & Pluralista & $\begin{array}{l}\text { Distinta e mais equilibrada que a } \\
\text { alcançada na } 1^{\text {a }} \mathrm{CE}\end{array}$ \\
\hline Para Mulheres & Pluralista cooperativa & $\begin{array}{l}\text { Maior para o movimento e as en- } \\
\text { tidades feministas }\end{array}$ \\
\hline $\begin{array}{l}\text { Promoção da Igualdade } \\
\text { Racial }\end{array}$ & Pluralista cooperativa & Maior para os movimentos negros \\
\hline
\end{tabular}

Fonte: A autora. 
influência na respectiva política tende a ser mais equilibrada, dados os fortes conflitos de interesse. Por fim, nas políticas para mulheres e de promoção da igualdade racial, espera-se que a capacidade de influência de cada ator na respectiva política reflita a distribuição de poder entre os mesmos na área, como mostra o Quadro 2.

$\mathrm{Na}$ próxima seção, examina-se se e em que medida os diferentes atores representados na $1^{\text {a }} \mathrm{CAP}, 1^{\mathrm{a}}$ Concidades, $1^{\mathrm{a}} \mathrm{CMA}, 1^{\mathrm{a}} \mathrm{CE}, 1^{\mathrm{a}} \mathrm{CPM}$ e $1^{\mathrm{a}} \mathrm{CPIR}$ influenciaram os programas governamentais da respectiva política setorial a partir das propostas finais nelas aprovadas. Também se compara tais resultados com a capacidade de influência dos atores não-governamentais na respectiva conferência, como mostrado por Petinelli (2017).

\title{
IV. Dinâmica política e capacidade de influência de atores não-governamentais nas políticas setoriais: os casos da $1^{\text {a }}$ CAP, $1^{\text {a }}$ Concidades, $1^{\text {a }}$ CMA, $1^{\text {a }}$ CE, $1^{\text {a }}$ CPM e $1^{\text {a }}$ CPIR
}

\author{
IV.1. Escopo e metodologia
}

Este trabalho avalia a relação entre a dinâmica política e atores beneficiados pelas propostas aprovadas em conferência e incorporadas aos programas governamentais da respectiva política, por meio da análise comparativa entre o conteúdo de tais propostas e o conteúdo dos programas de políticas elaborados após as conferências. Por "conteúdo" entende-se o objetivo, a finalidade e a intenção expressa na proposta, e não a redação ipsis litteres do texto.

Para empreender tal análise, o trabalho examina as propostas aprovadas na $1^{\text {a }}$ CAP, $1^{\text {a }}$ Concidades, $1^{\text {a }}$ CMA, $1^{\text {a }} \mathrm{CE}, 1^{\text {a }} \mathrm{CPM}$ e $1^{\mathrm{a}} \mathrm{CPIR}$. Avalia-se as propostas aprovadas (1) de competência exclusiva e compartilhada do Ministério ou Secretaria Especial organizador da conferência e (2) passíveis de incorporação em programas da política setorial.

A classificação por competência se justifica uma vez que todas as áreas de políticas passaram pelo processo de descentralização administrativa nas décadas de 1980 e de 1990, o qual ampliou o leque de instituições corresponsáveis pela gestão das áreas. Entre 2003 e 2006, a política nacional de aquicultura e pesca competia à Secretaria Especial de Aquicultura e Pesca (SEAP), a política urbana, ao Ministério das Cidades (Mcidades), a política nacional de meio ambiente ao Ministério do Meio Ambiente (MMA) e ao Ibama, a política de esporte ao Ministério do Esporte (ME) e as políticas para mulheres e de promoção da igualdade racial competiam à Secretaria Especial de Políticas para Mulheres (SPM) e à Secretaria Especial de Políticas de Promoção da Igualdade Racial (Seppir), respectivamente.

A classificação das propostas por competência foi realizada em três etapas. Primeiro, identificou-se as atribuições de cada ministério e secretaria especial no período. Em seguida, identificou-se, em cada proposta, a quem competiria sua execução. Por fim, classificou-se as propostas em: (0) de competência exclusiva da SEAP, Mcidades, MMA, ME, SPM e Seppir; (1) de competência compartilhada dessas instituições com outros ministérios e entes federados; ou (2) de competência de outras instituições e unidades federativas.

Identificadas as diretrizes de competência exclusiva e compartilhada da SEAP, MCidades, MMA, ME, SPM e da Seppir, e excluídas as de competência externa, aplicou-se o segundo critério: a forma de incorporação de cada proposta. Essa classificação foi necessária para identificar e excluir as propostas cuja incorporação passava pela elaboração de lei de iniciativa do Executivo ou do Legislativo, e não pela tradução da mesma em objetivo, princípio e/ou ação de programas do plano de ação da instituição competente. Neste sentido, as propostas foram classificadas como: (0) de incorporação via atos normativos ou 
(1) de incorporação via programas de políticas. Todas as propostas cuja incorporação ocorria via atos normativos foram excluídas do banco de dados. Assim, toda proposta visando a "proibir certas práticas, regulamentar, regularizar e/ou criar e revisar leis, critérios, instrumentos e mecanismos de regulação" foi excluída da análise.

Do total de 2.536 propostas aprovadas nos seis processos conferencistas, foram examinadas 1.694 de competência exclusiva e compartilhada do Ministério ou Secretaria Especial, organizador da conferência, e passíveis de incorporação em programas da política setorial (Tabela 1). Dessas, a $1^{\mathrm{a}} \mathrm{CPIR}, 1^{\mathrm{a}}$ CMA e a $1^{\text {a }}$ Concidades aprovaram o maior número de propostas, enquanto a $1^{\mathrm{a}}$ $\mathrm{CAP}, 1^{\mathrm{a}} \mathrm{CPM}$ e $1^{\mathrm{a}} \mathrm{CE}$ geraram a menor quantidade ao longo de todo o processo.

Buscou-se identificar o objetivo de cada proposta, comparando-o à ementa, objetivos, metas, estratégias e diretrizes dos programas da respectiva política. Nas seis áreas, o ministério ou a secretaria especial elaborou um plano de ação logo após as conferências, com os programas, ações e metas (Brasil 2004a; 2004b; 2004d; 2004e; 2005a; 2009). Comparando-se o conteúdo da proposta com o conteúdo dos programas da respectiva política, cada proposta foi, então, classificada em (0) incorporada, se incluída em alguma medida, ou (1) rejeitada, se integralmente desconsiderada. O Quadro 3 traz exemplos dessa análise. Nas propostas incorporadas parcialmente, destaca-se, em negrito, a proposta aprovada em conferência da demanda não-incorporada aos programas da política.

Tendo-se comparado o conteúdo de cada proposta com os programas da respectiva política, classificou-se as propostas incorporadas por ator(es) de interesse. Nessa classificação, considerou-se somente o ator interessado pela recomendação aprovada, não sendo considerado nem analisado se ele participou direta ou indiretamente de sua formulação. As discussões nas conferências acontecem geralmente em grupos de trabalho temáticos e em plenárias. Nos primeiros, um documento-base com propostas sugeridas é apreciado e, na maior parte dos casos, é facultado aos delegados sugerir novas propostas para apreciação no próprio grupo. Nas plenárias, por sua vez, há somente votação das propostas aprovadas nos grupos segundo critérios definidos no regulamento interno da conferência. Devido ao grande volume de propostas para apreciação e à curta duração do processo conferencista, os debates e votações são conduzidos de forma sistemática e célere, o que impossibilita a coleta de informações acerca do autor da proposta e do segmento e categoria que ele representa. Em decorrência disso, essa informação não é usualmente coletada e disponibilizada pela equipe organizadora das conferências.

As categorias de atores consideradas buscaram refletir tanto os grupos politicamente atuantes na respectiva política setorial (Quadro 1), como a com-

Tabela 1 - Propostas aprovadas na $1^{\mathrm{a}} \mathrm{CAP}, 1^{\mathrm{a}}$ Concidades, $1^{\mathrm{a}} \mathrm{CMA}, 1^{\mathrm{a}} \mathrm{CE}, 1^{\mathrm{a}} \mathrm{CPM}$ e $1^{\mathrm{a}}$ CPIR examinadas

\begin{tabular}{lcc}
\hline Conferência & Propostas aprovadas & Propostas examinadas \\
\hline $1^{\text {a }} \mathrm{CAP}$ & 175 & 175 \\
$1^{\text {a }}$ Concidades & 298 & 239 \\
$1^{\text {a } \mathrm{CMA}}$ & 652 & 429 \\
$1^{\text {a } \mathrm{CE}}$ & 103 & 87 \\
$1^{\text {a } \mathrm{CPM}}$ & 253 & 133 \\
$1^{\text {a } \mathrm{CPIR}}$ & 1.055 & 631 \\
Total & 2.536 & 1.694 \\
\hline
\end{tabular}

Fonte: A autora, com base em Brasil (2003a; 2003b; 2003c; 2004c; 2004e; 2005b). 
Quadro 3 - Relação (incorporação parcial, integral ou rejeição) entre o conteúdo das propostas aprovadas em conferência e o conteúdo dos programas das respectivas políticas

\begin{tabular}{|c|c|c|c|}
\hline Conferência & Conteúdo da proposta & Conteúdo do programa & Relação \\
\hline $1^{\text {a }} \mathrm{CAP}$ & $\begin{array}{l}\text { Promover a propaganda e o marketing do pesca- } \\
\text { do oriundo da aquicultura e da pesca, ressaltando } \\
\text { os benefícios do consumo de pescado para a saú- } \\
\text { de. }\end{array}$ & $\begin{array}{l}\text { Promover a propaganda e o marketing } \\
\text { do pescado oriundo da aquicultura e da } \\
\text { pesca, ressaltando os benefícios do } \\
\text { consumo de pescado para a saúde. }\end{array}$ & $\begin{array}{l}\text { Incorporação } \\
\text { Integral }\end{array}$ \\
\hline $1^{\text {a }}$ Concidades & $\begin{array}{l}\text { Desburocratizar e descentralizar os programas } \\
\text { federais. }\end{array}$ & - & Rejeição \\
\hline $1^{\mathrm{a}} \mathrm{CMA}$ & $\begin{array}{l}\text { Estimular e apoiar a realização dos planos de } \\
\text { bacia com a participação efetiva dos conselhos } \\
\text { municipais de meio ambiente, respeitando a } \\
\text { soberania dos respectivos comitês de bacias } \\
\text { hidrográficas e definindo diretrizes para a ela- } \\
\text { boração de planos diretores municipais. }\end{array}$ & $\begin{array}{l}\text { Programa } 1107 \text { Probacias: Elaboração } \\
\text { dos planos de bacias hidrográficas de } \\
\text { rios de domínios da União. Fomento à } \\
\text { criação de comitês e agências em ba- } \\
\text { cias hidrográficas de rios de domínio } \\
\text { da união. }\end{array}$ & $\begin{array}{l}\text { Incorporação } \\
\text { Parcial }\end{array}$ \\
\hline $1^{\mathrm{a}} \mathrm{CE}$ & $\begin{array}{l}\text { Elaborar e implementar ações que permitam } \\
\text { maior controle público dos programas do Minis- } \\
\text { tério do Esporte, visando sua democratização e } \\
\text { participação da sociedade civil. }\end{array}$ & $\begin{array}{l}\text { Garantir mecanismos de controle e } \\
\text { avaliação permanentes da Política } \\
\text { Nacional de Esporte, com a partici- } \\
\text { pação dos Conselhos e dos Gestores } \\
\text { Estaduais e Municipais e através da } \\
\text { Conferência, visando o } \\
\text { acompanhamento contínuo das ações } \\
\text { em todos os níveis de execução, para } \\
\text { direcionar e redirecionar seu processo } \\
\text { de planejamento }\end{array}$ & $\begin{array}{l}\text { Incorporação } \\
\text { Integral }\end{array}$ \\
\hline $1^{\text {a }} \mathrm{CPM}$ & $\begin{array}{l}\text { Estimular o compartilhamento das tarefas } \\
\text { domésticas através de uma maior liberação do } \\
\text { tempo das trabalhadoras que não incida na } \\
\text { remuneração e de campanhas institucio- } \\
\text { nais, construindo e reforçando uma nova cultura } \\
\text { referente à divisão sexual do trabalho. }\end{array}$ & $\begin{array}{l}\text { Estimular a divisão das tarefas do- } \\
\text { mésticas. }\end{array}$ & $\begin{array}{l}\text { Incorporação } \\
\text { parcial }\end{array}$ \\
\hline $1^{\text {a }}$ CPIR & $\begin{array}{l}\text { Estruturar um sistema de indicadores de raça e } \\
\text { gênero para a avaliação e monitoramento das } \\
\text { políticas públicas de geração de emprego e renda } \\
\text { e combate à discriminação racial e pobreza. }\end{array}$ & - & Rejeição \\
\hline
\end{tabular}

Fonte: A autora, com base em Brasil (2003a; 2003b; 2003c; 2004c; 2004e; 2005b).

posição da representação nos processos conferencistas examinados (Petinelli 2017). O Quadro 4 apresenta os atores considerados na política de aquicultura e pesca, urbana, de meio ambiente, de esporte, nas políticas para mulheres e de promoção da igualdade racial. Particularmente em relação à $1^{\mathrm{a}} \mathrm{CPM}$ e à $1^{\mathrm{a}}$ CPIR, não se diferenciou os movimentos (feministas e negros/indígenas) das entidades civis pela dificuldade em classificar as propostas de interesse de um e/ou de outro, dada a significativa similaridade de discursos e a interação colaborativa entre tais atores.

O Quadro 5 traz exemplos da classificação das propostas aprovadas e incorporadas, por ator de interesse. A classificação foi feita a partir da seguinte pergunta: "A quem interessa diretamente a aprovação da proposta"? Considerou-se somente o(s) ator(es) diretamente interessado(s) na proposta aprovada. Nesse sentido, identificou-se o objetivo de cada resposta e buscou-se associá-lo ao discurso e às demandas de algum ator no momento de realização da conferência. 
Quadro 4 - Atores considerados no âmbito da Política de Aquicultura e Pesca, Urbana, de Meio Ambiente, de Esporte, nas Políticas para Mulheres e de Promoção da Igualdade Racial

\begin{tabular}{ll}
\hline Política & Atores considerados \\
\hline Aquicultura e Pesca & Pescadores artesanais e aquicultores \\
& familiares \\
& Empresários da pesca e da aquicultura \\
& Entidades civis \\
& Governo \\
Mrbana & Movimentos urbanos \\
& Entidades civis, acadêmicas e de \\
pesquisa & Trabalhadores \\
Empresários \\
Operadores e concessionários \\
Governo \\
Movimentos ambientalistas \\
Entidades civis \\
Comunidades tradicionais e povos \\
indígenas \\
Empresários \\
Governo \\
Comunidade do esporte profissional \\
Comunidade do esporte educativo \\
Comunidade do esporte participativo \\
Governo \\
Movimentos feministas e entidades civis \\
Governo \\
Movimentos negros e entidades civis \\
Movimentos indígenas e entidades civis \\
\hline
\end{tabular}

Fonte: A autora, com base no Quadro 1 e em Petinelli (2017).

Uma vez identificado o(s) ator(es) de interesse de cada proposta, aferiu-se sua capacidade de influência, considerando-os individual e conjuntamente por meio de cálculo do percentual de propostas de interesse de cada ator em relação ao total de propostas incorporadas aos programas da respectiva política setorial.

Por fim, comparou-se os resultados obtidos com a capacidade de influência dos mesmos atores na $1^{\text {a }} \mathrm{CAP}, 1^{\mathrm{a}}$ Concidades, $1^{\mathrm{a}} \mathrm{CMA}, 1^{\mathrm{a}} \mathrm{CE}, 1^{\mathrm{a}} \mathrm{CPM}$ e $1^{\mathrm{a}}$ CPIR (Petinelli 2017). Os resultados são apresentados a seguir.

IV.2. Atores e capacidade de influência nas políticas setoriais: constatações a partir das propostas aprovadas na $1^{a} C A P, 1^{a}$ Concidades, $1^{a} C M A, 1^{a} C E, 1^{a} C P M$ e $1^{a} C P I R$

A Tabela 2 apresenta o total e a proporção de propostas aprovadas nas conferências e incorporadas aos programas governamentais. Como se verifica, mais da metade das propostas aprovadas na $1^{\mathrm{a}} \mathrm{CAP}, 1^{\mathrm{a}}$ Concidades, $1^{\mathrm{a}} \mathrm{CE}$ e $1^{\mathrm{a}}$ $\mathrm{CPM}$ foram incorporadas à respectiva política, com destaque para a $1^{\mathrm{a}} \mathrm{CAP}$, com $100 \%$, e para a $1^{a}$ Concidades, com mais de $75 \%$. Somente a $1^{\text {a }}$ CMA e a $1^{\text {a }}$ 
Quadro 5 - Exemplos de propostas aprovadas e incorporadas de interesse de atores por política

\begin{tabular}{|c|c|c|}
\hline Política & Ator(es) & Proposta aprovada e incorporada \\
\hline Aquicultura e Pesca & Todos & $\begin{array}{l}\text { Incentivo à criação de Conselhos Municipais, Estaduais, Fóruns } \\
\text { Microrregionais e Câmaras Técnicas Locais de Aquicultura, Pes- } \\
\text { ca e Pesquisa, para que em conjunto com o Conselho Nacional da } \\
\text { Aquicultura e Pesca integrem as entidades representativas destes } \\
\text { setores na construção democrática das políticas de } \\
\text { desenvolvimento em todas as esferas governamentais. }\end{array}$ \\
\hline Urbana & Movimentos urbanos & $\begin{array}{l}\text { A gestão democrática deve reconhecer a autonomia dos movi- } \\
\text { mentos sociais, sem discriminação, e estar sempre comprometida } \\
\text { com o direito universal a educação, saúde, moradia, trabalho, pre- } \\
\text { vidência social, transporte, meio ambiente saudável, cultura e } \\
\text { lazer. }\end{array}$ \\
\hline Meio Ambiente & Governo & $\begin{array}{l}\text { Viabilizar o Pacto Federativo, fortalecendo, sobretudo, a Comis- } \\
\text { são Tripartite como um dos grandes fóruns para a construção do } \\
\text { Pacto Ambiental do país, por meio da instalação e da consolida- } \\
\text { ção de comissões tripartites nos estados e bipartite no Distrito Fe- } \\
\text { deral, envolvendo representantes dos órgãos ambientais da } \\
\text { União, dos estados e dos municípios. }\end{array}$ \\
\hline Esporte & Esporte profissional & $\begin{array}{l}\text { Detectar e desenvolver talentos esportivos em potencial e apri- } \\
\text { morar o desempenho de atletas e para-atletas de rendimento. }\end{array}$ \\
\hline Para Mulheres & Sociedade civil & $\begin{array}{l}\text { Estabelecer estratégias que promovam equilíbrio de poder entre } \\
\text { mulheres e homens, em termos de recursos econômicos, direitos } \\
\text { legais, participação política e relações interpessoais }\end{array}$ \\
\hline $\begin{array}{l}\text { Promoção da } \\
\text { Igualdade Racial }\end{array}$ & Movimentos negros e governo & $\begin{array}{l}\text { Implementar, no serviço público, o programa de combate ao } \\
\text { racismo institucional. }\end{array}$ \\
\hline
\end{tabular}

Fonte: A autora, com base em Brasil (2003a; 2003b; 2003c; 2004c; 2004e; 2005b).

Tabela 2 - Propostas aprovadas na $1^{\mathrm{a}} \mathrm{CAP}, 1^{\mathrm{a}}$ Concidades, $1^{\mathrm{a}} \mathrm{CMA}, 1^{\mathrm{a}} \mathrm{CE}, 1^{\mathrm{a}} \mathrm{CPM}$ e $1^{\mathrm{a}}$ CPIR incorporadas à respectiva política setorial

\begin{tabular}{lccc}
\hline Conferência & $\begin{array}{c}\text { Propostas } \\
\text { aprovadas }\end{array}$ & $\begin{array}{c}\text { Propostas } \\
\text { incorporadas }\end{array}$ & Incorporação (\%) \\
\hline $1^{\text {a }}$ CAP & 175 & 175 & 100 \\
$1^{\text {a }}$ Concidades & 239 & 182 & 76,2 \\
$1^{\text {a }}$ CMA & 429 & 209 & 48,7 \\
$1^{\text {a }}$ CE & 87 & 51 & 58,6 \\
$1^{\text {a }}$ CPM & 133 & 80 & 60,1 \\
$1^{\text {a }}$ CPIR & 631 & 253 & 40 \\
Total & 1.694 & 943 & 55,7 \\
\hline
\end{tabular}

Fonte: A autora, com base em Brasil (2003a; 2003b; 2003c; 2004a; 2004b; 2004c; 2004d; 2004e; 2004f; 2005a; 2005b; 2009).

CPIR, que mais aprovaram propostas, tiveram menos de $50 \%$ delas incluídas à política de meio ambiente e de promoção da igualdade racial.

No total incorporado, observa-se uma variação expressiva quanto à capacidade de influência de cada ator não-governamental. A Tabela 3 apresenta a quantidade e o percentual de propostas da $1^{\mathrm{a}} \mathrm{CAP}, 1^{\mathrm{a}}$ Concidades, $1^{\mathrm{a}} \mathrm{CMA}, 1^{\mathrm{a}}$ $\mathrm{CE}, 1^{\mathrm{a}} \mathrm{CPM}$ e $1^{\mathrm{a}} \mathrm{CPIR}$ de interesse direto dos diversos atores individualmente 
Tabela 3 - Propostas incorporadas pós-processo conferencista de interesse direto de cada segmento considerado individualmente por política setorial (\%)

\begin{tabular}{|c|c|c|}
\hline Política & Ator beneficiado & $\begin{array}{c}\text { Propostas } \\
\text { incluídas }(\%)\end{array}$ \\
\hline \multirow{5}{*}{$\begin{array}{l}\text { Aquicultura e } \\
\text { Pesca }\end{array}$} & Pescadores artesanais e aquicultores familiares & $68(3)$ \\
\hline & Empresários & $3(3)$ \\
\hline & Entidades civis & $20(20)$ \\
\hline & Governo & $9(9)$ \\
\hline & Total Relativo & $100(57)$ \\
\hline \multirow[t]{7}{*}{ Urbana } & Movimentos urbanos & $90(70)$ \\
\hline & Entidades acadêmicas e de pesquisa & $4(3)$ \\
\hline & Trabalhadores & $3(3)$ \\
\hline & Empresários & $2(2)$ \\
\hline & Operadores e concessionários & $7(5)$ \\
\hline & Governo & $23(18)$ \\
\hline & Total Relativo & $129(71)$ \\
\hline \multirow[t]{6}{*}{ Meio Ambiente } & Movimentos ambientalistas & $42(53)$ \\
\hline & Entidades civis & $3(4)$ \\
\hline & Comunidades tradicionais e indigenas & $8(10)$ \\
\hline & Empresários & $3(4)$ \\
\hline & Governo & $24(30)$ \\
\hline & Total Relativo & $83(39)$ \\
\hline \multirow[t]{5}{*}{ Esporte } & Comunidade do esporte profissional & $2(22)$ \\
\hline & Comunidade do esporte educativo & $1(11)$ \\
\hline & Comunidade esporte participativo & $2(22)$ \\
\hline & Governo & $4(44)$ \\
\hline & Total Relativo & $9(18)$ \\
\hline \multirow[t]{3}{*}{ Para Mulheres } & Movimentos feministas e entidades civis & $68(92)$ \\
\hline & Governo & $6(8)$ \\
\hline & Total Relativo & $74(93)$ \\
\hline \multirow{5}{*}{$\begin{array}{l}\text { Promoção da } \\
\text { Igualdade Racial }\end{array}$} & Movimentos negros e entidades civis & $66(66)$ \\
\hline & Movimentos indigenas e entidades civis & $26(26)$ \\
\hline & Governo & $8(8)$ \\
\hline & Total Relativo & $100(40)$ \\
\hline & Total Parcial & $494(52)$ \\
\hline
\end{tabular}

Fonte: A autora, com base em Brasil (2003a; 2003b; 2003c; 2004a; 2004b; 2004c; 2004d; 2004e; 2004f; 2005a; 2005b; 2009).

incorporados aos programas governamentais. A Tabela 3 também traz o total e o percentual de propostas incorporadas em benefício de atores individuais em relação ao total de propostas incorporadas de cada conferência.

No que se refere à influência de cada ator, constata-se que, não obstante à significativa variação de capacidades, as organizações da sociedade civil foram as mais beneficiadas pelas propostas incorporadas em cinco dos seis processos conferencistas examinados. Somente na $1^{\text {a }} \mathrm{CE}$ a proporção de propostas de atores governamentais superou à da comunidade do esporte educativo e do 
esporte participativo, sendo semelhante ao somatório das propostas aprovadas de interesse dos atores não-governamentais.

$\mathrm{Na} 1^{\mathrm{a}} \mathrm{CAP}, 68 \%$ das recomendações aprovadas beneficiavam a comunidade de pescadores artesanais e aquicultores familiares e $20 \%$, as entidades civis com atuação no setor. $\mathrm{Na} 1^{\mathrm{a}}$ Concidades e na $1^{\mathrm{a}} \mathrm{CMA}$, em torno de $70 \%$ das propostas eram de interesse direto dos diferentes atores da sociedade civil, sendo mais de $50 \%$ delas de interesse direto dos movimentos sociais. Semelhantemente, as recomendações aprovadas na $1^{\text {a }}$ CPM e na $1^{\text {a }}$ CPIR incorporadas aos programas da Secretaria Especial de Políticas para Mulheres e da Secretaria Especial de Promoção da Igualdade Racial, respectivamente, beneficiavam em grande medida os movimentos sociais e entidades civis com atuação na área (mais de 90\% do total de propostas de interesse exclusivo de um ator).

No que diz respeito ao total de propostas incorporadas de interesse de um único ator em relação ao total aprovado nos seis processos conferencistas (Tabela 3), observa-se que, de 494 propostas aprovadas e incorporadas, 52\% beneficiavam apenas um ator. Em metade das conferências da $1^{\mathrm{a}} \mathrm{CAP}, 1^{\mathrm{a}}$ Concidades e $1^{\text {a }} \mathrm{CPM}$, a proporção de propostas incorporadas de interesse de um único ator superou a de propostas aprovadas de interesse de dois ou mais atores (Tabela 4). Nas demais, $1^{\text {a }} \mathrm{CMA}, 1^{\mathrm{a}} \mathrm{CE}$ e $1^{\mathrm{a}} \mathrm{CPIR}$, a quantidade de propostas em benefício de atores individuais foi inferior à de dois ou mais atores.

Resultados semelhantes quanto à capacidade de influência dos diferentes grupos não-governamentais sobre as propostas incorporadas na respectiva política pós-conferência são observados ao se analisar as propostas de interesse direto de dois ou mais atores conjuntamente. Como mostrado pela Tabela 4, acima, os atores mais influentes individualmente, em cada área de política, também se beneficiaram, em maior medida, das propostas de interesse de dois ou mais grupos. Tanto na $1^{\text {a }} \mathrm{CAP}$ e $1^{\mathrm{a}} \mathrm{CE}$, quanto na $1^{\mathrm{a}} \mathrm{CPM}$ e $1^{\mathrm{a}} \mathrm{CPIR}$, o total de propostas incorporadas interessavam, em boa medida, aos atores sociais. Já na $1^{\mathrm{a}}$ Concidades e $1^{\mathrm{a}} \mathrm{CMA}$, mais de $60 \%$ das recomendações incorporadas beneficiavam os grupos da sociedade civil, e o restante, aos atores de mercado e governamentais.

Ademais, é interessante observar que, na política de aquicultura e pesca, do total de propostas de interesse de dois ou mais atores, incorporadas à política final, $60 \%$ delas beneficiavam, conjuntamente, pescadores, aquicultores e empresários da pesca e aquicultura. Por outro lado, nas áreas de dinâmica política pluralista, a distribuição de propostas de interesse de dois ou mais atores foi mais dispersa, sendo a incidência maior entre atores sociais. Na política urbana, os movimentos urbanos e entidades de pesquisa conquistaram $13 \%$ das propostas compartilhadas e incorporadas à política final. Na política de meio ambiente, os movimentos ambientalistas e entidades civis da área se beneficiaram de $42 \%$ do total e, na política de esporte, a comunidade de esporte educativo e a de esporte participativo conquistaram $45 \%$ das propostas. Por fim, havendo interação cooperativa entre os atores, como na política de promoção da igualdade racial, quase a totalidade das propostas incorporadas de interesse de dois ou mais atores respondia a demandas dos movimentos e entidades civis.

Agregando a capacidade de influência individual e compartilhada, por ator, observa-se uma expressiva influência dos atores sociais em relação ao total de propostas aprovadas em conferência e incorporadas aos programas da respectiva política setorial. Nas políticas para mulheres e de promoção da igualdade racial, os movimentos feministas, de negros, indígenas e as entidades civis com atuação nessas áreas beneficiaram-se de $86 \%$ e $96 \%$ do total de propostas aprovadas e incorporadas após a $1^{\text {a }} \mathrm{CPM}$ e a $1^{\mathrm{a}} \mathrm{CPIR}$, respectivamente. $\mathrm{Na}$ política urbana, por outro lado, em que pese a significativa influência dos movimentos urbanos e entidades civis $(58 \%$ do total de propostas incorporadas 
Tabela 4 - Propostas incorporadas após o processo conferencista de interesse direto de dois ou mais segmentos, por política setorial

\section{Política}

Aquicultura e Pesca

\section{Ator beneficiado}

Pescadores/ aquicultores e empresários

Pescadores/ aquicultores e entidades civis

Pescadores/ aquicultores e governo

Entidades civis e governo

Pescadores/ aquicultores, empresários e entidades civis

Todos

Total Relativo

Urbana

Meio Ambiente

Para Mulheres

Promoção da Igualdade Racial
Movimentos urbanos e entidades de pesquisa

Movimentos urbanos e empresários

Movimentos urbanos e operador/ concessionário

Movimentos urbanos e governo

Entidades de pesquisa e operador/ concessionário

Entidades de pesquisa e governo

Trabalhadores e empresários

Empresários e operador/ concessionário

Empresários e governo

Operador/ concessionário e governo

Movimentos, entidades, trabalhadores, empresários e operadores/ concessionários

Todos

Total Relativo

Movimentos ambientalistas e empresários

Movimentos ambientalistas e governo

Movimentos ambientalistas e comunidades

Movimentos ambientalistas e entidades civis

Comunidades tradicionais e entidades civis

Entidades civis e governo

Movimentos, comunidades e entidades

Movimentos, comunidades, entidades e governo

Movimentos, comunidades, entidades e empresários

Todos

Total Relativo

Esporte educativo e participativo

Esporte educativo e governo

Esporte educativo, participativo e profissional

Todos

Total Relativo

Movimentos feministas, entidades civis e governo

Total Relativo

Movimento negro e indígena e entidades civis

Movimento negro e indígena, entidades civis e governo

Total Relativo

Total Parcial
Propostas incluídas (\%)

$45(60)$

$3(4)$

$1(1)$

$16(21)$

$6(11)$

$6(11)$

$10(19)$

$2(4)$

3 (6)

$1(2)$

$2(4)$

$1(2)$

$2(4)$

8 (15)

53 (29)

49 (42)

2 (2)

14 (12)

4 (3)

8 (7)

$6(5)$

$126(61)$

8 (19)

$6(100)$

$146(95)$

$153(60)$

449 (48)

Fonte: A autora, com base em Brasil (2003a; 2003b; 2003c; 2004a; 2004b; 2004c; 2004d; 2004e; 2004f; 2005a; 2005b; 2009). 
Tabela 5 - Capacidade total de influência dos atores na política setorial

\begin{tabular}{|c|c|c|}
\hline Política & Ator & Capacidade de influência (\%) \\
\hline \multirow[t]{4}{*}{ Aquicultura e Pesca } & Pescadores artesanais e aquicultores familiares & 50 \\
\hline & Empresários da pesca e aquicultura & 25 \\
\hline & Entidades civis com atuação na área & 18 \\
\hline & Governo & 7 \\
\hline \multirow[t]{6}{*}{ Urbana } & Movimentos urbanos & 48 \\
\hline & Entidades acadêmicas e de pesquisa & 10 \\
\hline & Trabalhadores & 6 \\
\hline & Empresários & 9 \\
\hline & Operadores e concessionários & 12 \\
\hline & Governo & 15 \\
\hline \multirow[t]{5}{*}{ Meio Ambiente } & Movimentos ambientalistas & 42 \\
\hline & Empresários & 7 \\
\hline & Entidades civis & 26 \\
\hline & Comunidades tradicionais e indigenas & 11 \\
\hline & Governo & 15 \\
\hline \multirow[t]{4}{*}{ Esportes } & Comunidade do esporte profissional & 18 \\
\hline & Comunidade do esporte educativo & 34 \\
\hline & Comunidade esporte participativo & 33 \\
\hline & Governo & 15 \\
\hline \multirow[t]{2}{*}{ Para Mulheres } & Sociedade civil & 86 \\
\hline & Governo & 14 \\
\hline \multirow[t]{3}{*}{ Promoção da Igualdade Racial } & Movimentos negros e entidades civis & 53 \\
\hline & Movimentos indígenas e entidades civis & 43 \\
\hline & Governo & 4 \\
\hline
\end{tabular}

Fonte: A autora, com base nas Tabela 3 e 4.

eram de seu interesse), os atores de mercado - empresários e trabalhadores, operadores e concessionários - e os atores governamentais beneficiaram-se de $42 \%$. Nas demais áreas, a influência dos atores sociais ficou em torno de $70 \%$ (Tabela 5).

Esses resultados parecem estar relacionados, em alguma medida, à dinâmica política nessas áreas. Como visto na seção anterior, cada política apresenta uma dinâmica política particular: enquanto a política de aquicultura e pesca assume uma dinâmica mais corporativista, as demais apresentam redes pluralistas ou mais competitivas (como a política urbana, de meio ambiente e a de esporte) ou mais cooperativas (como as políticas para mulheres e de promoção da igualdade racial) (Quadro 2). Em contextos mais corporativos, com menos atores e um padrão de interação mais cooperativo, haveria fortes incentivos à colaboração e à aceitação de resultados gerados por meio de espaços de discussão e tomada de decisão conjunta, como as conferências. Nas áreas com dinâmica pluralista, por sua vez, os conflitos de interesse ora mais, ora menos acentuados tenderiam a produzir resultados mais equilibrados e mais condizentes com a posição de poder ocupada por cada ator na respectiva política.

Disso se esperaria: 1) na política de aquicultura e pesca, uma capacidade de influência por ator semelhante no resultado final da conferência e na política subsequente; (2) na política urbana, de meio ambiente e de esporte, uma 
capacidade de influência mais equilibrada e distinta por ator na conferência e na política; (3) nas políticas para mulheres e de promoção da igualdade racial, uma capacidade de influência maior, tanto nas conferências como na política, dos atores politicamente mais proeminentes na área, no caso, os movimentos sociais e entidades civis.

A Tabela 6 mostra a capacidade de influência total dos atores na conferência (Petinelli 2017) e na política setorial. Como se constata, foram muito próximas a proporção total de propostas aprovadas nas conferências e a proporção de propostas incorporadas aos programas governamentais de interesse de cada ator. De modo geral, os seis processos conferencistas serviram, notoriamente, como espaços de empoderamento da participação e de influência de atores sociais na respectiva política setorial. Pescadores artesanais e aquicultores familiares, movimentos urbanos, movimentos ambientalistas e entidades civis da área, comunidade do esporte educativo e do esporte participativo, e os movimentos sociais e entidades civis com atuação nas políticas para mulheres e de promoção da igualdade racial não só influenciaram, em maior medida, o resultado final da conferência, como tiveram as propostas de seu interesse incorporadas em maior medida à política subsequente.

Tabela 6 - Capacidade total de influência dos atores na conferência e na política setorial (\%)

\begin{tabular}{|c|c|c|c|}
\hline \multirow[t]{2}{*}{ Conferência/ Política } & \multirow[t]{2}{*}{ Ator } & \multicolumn{2}{|c|}{ Capacidade de influência } \\
\hline & & Conferência & Política setorial \\
\hline \multirow{4}{*}{$1^{\mathrm{a}} \mathrm{CAP} /$ Aquicultura e Pesca } & Pescadores artesanais e aquicultores familiares & 50 & 50 \\
\hline & Empresários da pesca e aquicultura & 26 & 25 \\
\hline & Entidades civis com atuação na área & 17 & 18 \\
\hline & Governo & 7 & 7 \\
\hline \multirow[t]{6}{*}{$1^{\text {a }}$ Concidades/ Urbana } & Movimentos urbanos & 49 & 48 \\
\hline & Entidades acadêmicas e de pesquisa & 12 & 10 \\
\hline & Trabalhadores & 5 & 6 \\
\hline & Empresários & 8 & 9 \\
\hline & Operadores e concessionários & 12 & 12 \\
\hline & Governo & 14 & 15 \\
\hline \multirow[t]{5}{*}{$1^{a} \mathrm{CMA} /$ Meio Ambiente } & Movimentos ambientalistas & 41 & 42 \\
\hline & Empresários & 9 & 7 \\
\hline & Entidades civis & 26 & 26 \\
\hline & Comunidades tradicionais e indigenas & 14 & 11 \\
\hline & Governo & 10 & 15 \\
\hline \multirow[t]{4}{*}{$1^{\mathrm{a}} \mathrm{CE} /$ Esportes } & Comunidade do esporte profissional & 18 & 18 \\
\hline & Comunidade do esporte educativo & 38 & 34 \\
\hline & Comunidade do esporte participativo & 32 & 33 \\
\hline & Governo & 12 & 15 \\
\hline \multirow[t]{2}{*}{$1^{\text {a }} \mathrm{CPM} /$ Para Mulheres } & Sociedade civil & 88 & 86 \\
\hline & Governo & 12 & 14 \\
\hline \multirow{3}{*}{$\begin{array}{l}1^{\text {a }} \text { CPIR/Promoção da } \\
\text { Igualdade Racial }\end{array}$} & Movimentos negros e entidades civis & 58 & 53 \\
\hline & Movimentos indígenas e entidades civis & 38 & 43 \\
\hline & Governo & 4 & 4 \\
\hline
\end{tabular}

Fonte: A autora, com base em Petinelli (2017) e a Tabela 5. 
Na política de aquicultura e pesca, os empresários perderam 1 ponto percentual em capacidade de influência para as entidades civis, enquanto que, nas políticas para mulheres e de promoção da igualdade racial, o governo e os movimentos indígenas, respectivamente, ganharam 2 e 5 pontos percentuais em capacidade de influência na política em relação aos movimentos feministas e negros.

Na política urbana, de meio ambiente e de esporte, por sua vez, a disputa entre os atores provocou maior variação. Na primeira, os movimentos urbanos e entidades acadêmicas perderam capacidade de influência para trabalhadores, empresários e para o governo. Já na política ambiental, os movimentos ambientalistas e o governo influenciaram mais o processo de políticas comparativamente ao resultado final da $1^{\mathrm{a}} \mathrm{CMA}$. Por último, quanto à política de esporte, a comunidade de esporte participativo e o governo ampliaram sua capacidade de influência na política, enquanto a comunidade de esporte educativo a perdeu (Tabela 6).

Tais constatações corroboram, em boa medida, as assumpções deste trabalho. Por hipótese, na política de aquicultura e pesca, a capacidade de influência de cada ator no resultado final da conferência se refletiria na respectiva política, enquanto nas políticas setoriais com redes pluralistas conflituosas, como a política urbana, de meio ambiente e de esporte, e cooperativas, como as políticas para mulheres e de promoção da igualdade racial, a capacidade de influência na respectiva política tenderia a ser mais equilibrada e próxima do poder de influência de cada ator na área, respectivamente.

Como suposto, a capacidade de influência de pescadores artesanais, aquicultores familiares, empresários da pesca e aquicultura e entidades civis da área na $1^{\mathrm{a}} \mathrm{CAP}$ foi, quando não idêntica, muito próxima da influência desses atores na política de aquicultura e pesca. As relações de cooperação entre os atores governamentais e não-governamentais e entre os atores não-governamentais nessa área parecem ter legitimado os resultados acordados em conferência, favorecendo, assim, a reprodução da capacidade de influência de cada ator na conferência na política setorial.

Por sua vez, nas políticas para mulheres e de promoção da igualdade racial, embora o governo e os movimentos indígenas tenham ampliado sua capacidade de influência na política em relação à alcançada na conferência, não houve alteração substantiva no poder de influência de cada ator na política. Como se esperava, as relações de cooperação entre os atores não-governamentais e entre estes e os atores governamentais levou à reprodução da posição de influência de cada ator na área, não obstante a dispersão de poder. Movimentos e entidades feministas e movimentos negros e entidades de promoção da igualdade racial beneficiaram-se, em maior medida, das propostas incorporadas às políticas para mulheres e de promoção da igualdade racial após a $1^{\mathrm{a}} \mathrm{CPM}$ e a $1^{\mathrm{a}} \mathrm{CPIR}$.

Já na política urbana, de meio ambiente e de esporte, a dispersão de poder e a disputa por influência no processo de políticas teriam possibilitado que certos atores ganhassem em influência, enquanto outros perdessem, em alguma medida, tal capacidade. Na política urbana, trabalhadores, empresários e o governo tiveram maior poder de influência, enquanto, na política ambiental, os movimentos ambientalistas e o governo foram mais exitosos. Já na política de esporte, a comunidade de esporte participativo e o governo ampliaram sua capacidade de influência na política. Da dinâmica competitiva entre esses atores, teria resultado, portanto, a maior variação entre a capacidade de influência dos mesmos alcançada em conferência e na política setorial.

Entretanto, diferentemente do esperado, a disputa entre os atores não-governamentais no processo das três políticas não redistribuiu e tornou mais equili- 
brada a capacidade de influência dos mesmos na política urbana, de meio ambiente e de esporte. Pelo contrário, a dinâmica política nada ou muito pouco afetou a capacidade de influência de cada ator na política a partir das propostas de seu interesse aprovadas na $1^{\mathrm{a}}$ Concidades, $1^{\mathrm{a}} \mathrm{CMA}$ e $1^{\mathrm{a}} \mathrm{CE}$. Os atores mais e menos influentes nas conferências também o foram na política setorial.

Análises como a de D’Araújo (2009) e de Abers, Serafim e Tatagiba (2014) contribuem para a compreensão desse resultado. A ocupação de cargos públicos de alto escalão por atores societais e a diversificação no repertório de interação desses atores com o Estado explicariam a reprodução, na política setorial, da capacidade de influência dos distintos atores societais na conferência. Os segmentos com atores societais em importantes cargos políticos teriam suas propostas defendidas tanto nos espaços participativos, como as conferências, como nos momentos de tomada de decisão dentro das instituições. Já os atores societais sem ou com menor representação, se utilizariam de outras práticas e canais, que não as conferências, para influenciar, em maior medida, a política formulada. Como decorrência, a capacidade de influência dos diferentes atores na conferência teria se replicado no processo de produção das políticas nos anos seguintes.

\section{Conclusões}

O processo de políticas públicas passou, nos últimos anos, por um intenso movimento de democratização que ampliou expressivamente a quantidade de atores societais em cargos governamentais e de espaços de participação de atores não-governamentais no âmbito do mesmo. Novas ideias, interesses e demandas passaram a ecoar e a disputar, ora pelo discurso ora pela negociação e barganha política, as diferentes políticas públicas. Nesse processo, alguns grupos têm sido mais favorecidos.

A capacidade de influência de cada ator no processo de políticas é afetada pela dinâmica política da área em que atua. Cada política setorial apresenta um tipo de rede de atores com repertórios de ação política distintos, o que dá origem a dinâmicas políticas próprias. Nas políticas setoriais que abrigam poucos grupos de interesse, atuantes de modo cooperativo (padrão clientelista/corporativista), o poder é mais concentrado e os custos de coordenação são menores, o que tende a favorecer a capacidade de influência de cada ator na respectiva política. Já nas políticas setoriais cujo conjunto de atores é amplo e diversificado (padrão das redes temáticas e pluralistas), a capacidade de influência de cada ator tende a ser menor, dada a maior dispersão do poder. Nessas áreas, os custos de coordenação dos variados interesses em disputa tendem a ser mais elevados, o que tende a reduzir ainda mais a capacidade de influência de cada ator.

Diante desses efeitos do tipo de rede na capacidade dos atores não-governamentais de influenciar o processo de políticas, este trabalho investigou se e como a dinâmica política impacta a capacidade de influência de atores não-governamentais nas políticas públicas a partir de instituições participativas. Nesse sentido, avaliou as propostas aprovadas na $1^{\text {a }}$ Conferência de Aquicultura e Pesca, de Cidades, de Meio Ambiente, na $1^{\text {a }}$ Conferência de Esporte, de Políticas para Mulheres e de Políticas de Promoção da Igualdade Racial, que foram incorporadas aos programas da respectiva política nos anos seguintes. $\mathrm{O}$ trabalho comparou o conteúdo das propostas aprovadas de interesse de cada ator representado na conferência com o conteúdo dos programas da política setorial e, a partir disso, mensurou a capacidade de influência de cada ator na política, por meio das propostas de seu interesse aprovadas em conferência. Nessa análise, foi desconsiderado, porém, o ator formulador ou modificador da proposta, pela ausência de dados a esse respeito. 
Por hipótese, a capacidade de influência de cada ator seria favorecida por um padrão de interação entre atores mais cooperativo, como observado para a política de aquicultura e pesca, as políticas para mulheres e de promoção da igualdade racial, enquanto um contexto de competição entre os atores reduziria a capacidade dos mesmos de influenciar determinada política, como esperado para a política urbana, de meio ambiente e de esporte. Havendo cooperação, a capacidade de influência dos atores na conferência e na área se reproduziria na política, enquanto uma interação mais competitiva geraria uma capacidade de influência por ator distinta da alcançada na conferência e mais equilibrada na política setorial.

No que se refere à capacidade de influência na política setorial, a análise mostrou a expressiva influência dos atores sociais presentes em cada área no total de propostas das conferências incorporadas às políticas. Tanto em relação às propostas de interesse exclusivo, como às de interesse compartilhado com outro(s) ator(es), observou-se influência mais expressiva de pescadores artesanais e aquicultores familiares, movimentos urbanos, movimentos ambientalistas e entidades civis da área, da comunidade do esporte educativo e do esporte participativo, e de movimentos sociais e entidades civis com atuação nas políticas para mulheres e de promoção da igualdade racial.

Ao comparar tais resultados alcançados por ator com sua capacidade de influência na conferência, constatou-se que a dinâmica política contribuiu para a menor ou maior variação na capacidade dos atores de influenciar a política a partir das propostas de seu interesse nela aprovadas. Como suposto, na política de aquicultura e pesca, a capacidade de influência de pescadores, aquicultores familiares, empresários e entidades civis na $1^{\mathrm{a}} \mathrm{CAP}$ foi, quando não idêntica, muito próxima à influência nos programas da política. Semelhantemente, nas políticas para mulheres e de promoção da igualdade racial, a dinâmica política pluralista-cooperativa possibilitou que os atores sociais mais influentes nas duas áreas - movimento feminista, movimentos negros e entidades civis com essas bandeiras - lograssem mais êxito tanto na conferência, como na política.

Por outro lado, como também esperado, na política urbana, de meio ambiente e de esporte, a disputa entre os atores provocou variação mais expressiva entre a capacidade de influência dos mesmos na conferência e na política. A dispersão de poder, somada à competição mais acirrada pelas políticas, levou a perdas de influência por alguns atores e ganhos por outros.

No entanto, diferentemente do suposto, esse trade-off não gerou uma distribuição mais equilibrada da capacidade de influência de cada ator na política. Pelo contrário, o poder relativo de influência de cada grupo na conferência se reproduziu no processo de políticas: os atores mais influentes na $1^{\text {a }}$ Concidades, $1^{\mathrm{a}} \mathrm{CMA}$ e $1^{\mathrm{a}} \mathrm{CE}$ também influenciaram mais a política urbana, de meio ambiente e de esporte a partir das propostas aprovadas nos processos conferencistas.

Esse resultado pode ser compreendido, em boa medida, ao se considerar o contexto político-institucional no primeiro mandato de Lula (2003-2006), caracterizado pela ocupação de cargos governamentais de alto escalão por atores societais e pela proliferação de experiências participativas na produção de políticas públicas. Como aponta D’Araújo (2009) e Abers, Serafim e Tatagiba (2014), os ativistas nesses cargos defenderam suas bandeiras e seus aliados políticos e buscaram construir e fortalecer os espaços participativos para promover e legitimar suas propostas para a política. Dessa atuação parece ter resultado a reprodução, na política setorial, da capacidade de influência dos distintos atores societais na conferência. 
Diante dessas constatações, é possível sugerir, pelo menos para o desenho de pesquisa aqui proposto, que a capacidade de influência das conferências na respectiva política setorial varia não só por política, como também por ator nela representado. Tal variação está diretamente associada ao desenho institucional da conferência, como mostrado por Petinelli (2017), e à dinâmica política da área, analisada neste trabalho. $\mathrm{O}$ desenho institucional da conferência afeta as propostas aprovadas de interesse de cada ator ao longo do processo, enquanto a dinâmica política impacta, em maior ou menor medida, a reprodução de tais resultados em termos de propostas incorporadas à respectiva política setorial.

Embora sejam espaços potencialmente plurais e inclusivos, as conferências podem gerar resultados pouco representativos dessa diversidade em decorrência do desenho que assumem e da dinâmica política na área em que são realizadas. Desenhos que privilegiam a representação de um ou outro ator, num contexto de interação cooperativa, tendem a favorecer a capacidade desigual de influência nas conferências e na respectiva política. Da mesma forma, desenhos que distribuem a representação dos diferentes atores de modo mais equilibrado não necessariamente gerarão capacidade de influência mais balanceada entre os atores na política, haja vista os efeitos da dinâmica política nesse processo.

Ressalte-se, porém, que as constatações e reflexões aqui apresentadas se aplicam unicamente à análise proposta, cujo desenho foi construído a partir de um conjunto de critérios metodológicos rígidos aplicados a seis casos específicos. Investigações que busquem comprovar a capacidade de influência dos atores societais nas políticas públicas deverão utilizar uma análise longitudinal dos resultados das conferências, podendo chegar a conclusões distintas.

Viviane Petinelli e Silva (vpetinelli@ hotmail.com) é Pós-Doutora em Ciência Política pela Universidade Federal de Minas Gerais (UFMG) e consultora política. Vínculo institucional: Departamento de Ciência Política, Universidade Federal de Minas Gerais, Belo Horizonte, MG, Brasil.

\section{Referências}

Abers, R.; Serafim, L. \& Tatagiba, L., 2014. Repertórios de Interação Estado-Sociedade em um Estado Heterogêneo: A Experiência na Era Lula. Dados, 57(2), pp.325-357. DOI: 10.1590/0011-5258201411

Almeida, D.R., 2013. Representação Política e Conferências: Os Desafios da Inclusão da Pluralidade. In L. Avritzer \& C.H.L. Souza, eds. Conferências Nacionais: atores, dinâmicas e efetividade. Brasília: IPEA.

Avritzer, L., 2013. Conferências Nacionais: ampliando e redefinindo os padrões de participação social no Brasil. In L. Avritzer \& C.H.L. Souza, eds. Conferências Nacionais: atores, dinâmicas e efetividade. Brasília: IPEA.

Bachrach, P. \& Baratz, M.S., 1962. Two Faces of Power. The American Political Science Review, 56(4), pp.947-952. DOI: $10.2307 / 1952796$

Bassul, J.R., 2002. Reforma urbana e Estatuto da Cidade. EURE, 28(84). DOI: 10.4067/s0250-71612002008400008

Boszczowski, A.C. \& Borghetti, J.B., 2006. Fortalecimento Institucional da Secretaria Especial de Aquicultura e Pesca SEAP/PR: Revisão do Marco Institucional, da Estrutura Institucional e Organizacional da SEAP/PR. Projeto FAO TCP/BRA 3001. Brasília: Secretaria Especial de Aquicultura e Pesca.

Bueno, L., 2008. Políticas públicas do esporte no Brasil: razões para o predomínio do alto rendimento. Tese de Doutorado. São Paulo: Escola de Administração de Empresas de São Paulo.

Costa, A. A.A., 2005. O movimento feminista no Brasil: dinâmicas de uma intervenção política. Niterói, 5(2), pp.9-35. DOI: 10.22409/rg.v5i2.380

Cunha, E.S.M, 2013. Conferências de políticas públicas e inclusão participativa. In L. Avritzer \& C.H.L. Souza, eds. Conferências Nacionais: atores, dinâmicas e efetividade. Brasília: IPEA.

D’Araújo, M.C., 2009. A Elite Dirigente do Governo Lula. Rio de Janeiro: FGV.

Dye, T.D., 1984. Understanding Public Policy. New Jersey: Prentice Hall.

Faria, C.F. \& Lins, I.L., 2013. Conferências Locais, Distritais e Municipais De Saúde: mudança de escala e formação de um sistema participativo, representativo e deliberativo de políticas públicas. In L. Avritzer \& C.H.L. Souza, eds. Conferências Nacionais: atores, dinâmicas e efetividade. Brasília: IPEA.

Fischer, F., 2003. Reframing Public Policy: Discursive Politics and Deliberative Practices. Oxford: Oxford University Press.

Haas, P.M., 1992. Introduction: Epistemic Communities and International Policy Coordination. International Organization, 46(1), pp.1-32. DOI: 10.1017/s0020818300001442 
Heclo, H., 2015. Issue Networks and the Executive Establishment. In M. Lodge; E.C. Page \& S.J. Balla, eds. The Oxford Handbook of Classics in Public Policy and Administration. Oxford: Oxford University Press.

Lavalle, A.G. \& Szwako, J., 2015. Sociedade civil, Estado e autonomia: argumentos, contra-argumentos e avanços no debate. Opinião Pública, 21(1), pp.157-187. DOI: 10.1590/1807-0191211157

Marques, E., 2013. Government, Political Actors and Governance in Urban Policies in Brazil and São Paulo: Concepts for a Future Research Agenda. Brazilian Political Science Review, 7(3), pp.8-35. DOI: 10.1590/s1981-38212013000300001

Petinelli, V., 2013. Contexto Político, Natureza da Política, Organização da sociedade civil e desenho institucional: alguns condicionantes da efetividade das Conferências Nacionais. In L. Avritzer \& C.H.L. Souza, eds. Conferências Nacionais: atores, dinâmicas e efetividade. Brasília: IPEA.

Petinelli, V., 2014. Uma análise dos condicionantes da capacidade de influência das conferências de políticas públicas sobre os programas das respectivas políticas setoriais: o caso da $1^{a}$ CAP, $1^{a}$ Concidades, $1^{a} C M A, 1^{a} C E, 1^{a} C P M$ e $1^{a} C P I R$. Tese de Doutorado. Belo Horizonte: Universidade Federal de Minas Gerais.

Petinelli, V., 2015. Aferindo a capacidade de influência das conferências de políticas públicas sobre os programas de políticas. Opinião Pública, 21, pp.643-672. DOI: 10.1590/1807-01912015213643

Petinelli, V., 2017. A quem servem as conferências de políticas públicas? A relação entre desenho institucional e atores beneficiados pelas recomendações aprovadas no respectivo processo. Opinião Pública, 23(3), pp.612-646. DOI: $10.1590 / 1807-01912017233612$

Pogrebinschi, T., 2013. Conferências Nacionais e Políticas Públicas para Grupos Minoritários. In L. Avritzer \& C.H.L. Souza, eds. Conferências Nacionais: atores, dinâmicas e efetividade. Brasília: IPEA.

Pogrebinschi, T. \& Santos, F., 2011. Participação como Representação: O Impacto das Conferências Nacionais de Políticas Públicas no Congresso Nacional. Dados, 54(3), pp.259-305. DOI: 10.1590/s0011-52582011000300002

Ramos, A. \& Faria, C.F., 2013. Las Conferencias de Políticas Públicas en Brasil: hacia un sistema integrado de participación y deliberación a nivel nacional. Revista Española de Ciencia Política, 32, pp.43-63.

Ribeiro, M., 2009. As políticas de igualdade racial no Brasil. Revista Análises e Propostas, 35.

Rhodes, R.A.W., 2006. Policy Network Analysis. In R. Goodin; M. Rein \& M. Moran, eds. The Oxford Handbook of Public Policy. Oxford: Oxford University Press.

Romão, W.M. \& Martelli, C.G., 2013. Estudos sobre as instituições participativas: o debate sobre sua efetividade. Revista Pensamento e Realidade, 28(1), pp.124-142.

Schmitter, P., 1974. Still the Century of Corporativism? The Review of Politics, 36(1), pp.85-131. DOI: 10.1017/S0034670500022178

Vieira, L. \& Cader, R., 2007. A política ambiental do Brasil ontem e hoje. Revista Eco, 129. Disponível em: http://www.eco21.com.br/textos/textos.asp?ID=1601. Acesso em: 22 dez. 2018.

Waarden, F.V., 1992. Dimensions and Types of Policy Networks. European Journal of Political Research, 21(1-2), pp.29-52. DOI: $10.1111 / j .1475-6765.1992 . t b 00287 . x$

Yannoulas, S. \& Soares, K., 2009. Políticas transversais (gênero, raça/etnia e deficiência) e educação/qualificação para o trabalho. Educação Unisinos, 13(1), pp.31-42. DOI: 10.4013/edu.2009.131.03

\section{Outras fontes}

Brasil, Presidência da República, 2003a. Caderno de resoluções da $1^{a}$ Conferência Nacional de Aquicultura e Pesca. Brasília: SEAP/PR.

Brasil, Ministério das Cidades, 2003b. Resoluções da $1^{a}$ Conferência Nacional das Cidades. Brasília: Mcidades.

Brasil, Ministério do Meio Ambiente, 2003c. Recomendações da $1^{a}$ Conferência Nacional de Meio Ambiente. Brasília: Ministério do Meio Ambiente.

Brasil, Presidência da República, 2004a. Plano Estratégico de Desenvolvimento Sustentável de Aquicultura e Pesca. Brasília: SEAP/PR.

Brasil, Ministério das Cidades, 2004b. Cadernos Mcidades. Brasília: Ministério das Cidades.

Brasil, Ministério do Esporte, 2004c. Conferência Nacional do Esporte. Esporte, Lazer e Desenvolvimento Humano: documento final. Brasília: Ministério do Esporte.

Brasil, Ministério do Esporte, 2004d. Política Nacional do Esporte. Brasília: Ministério do Esporte. Disponível em: http://www.esporte.gov.br/arquivos/politicaNacional/politicaNacionalCompleto.pdf. Acesso em: 25 dez. 2018.

Brasil, Presidência da República, 2004e. $1^{a}$ Conferência Nacional de Políticas para Mulheres. Brasília.

Brasil, Presidência da República, 2004f. Plano Nacional de Políticas para as Mulheres.

Brasil, Ministério do Meio Ambiente, 2005a. Vamos cuidar do Brasil. In I Conferência Nacional de Meio Ambiente. Ações do MMA para as deliberações da $1^{a}$ CMA. Brasília.

Brasil, Presidência da República, 2005b. Relatório Final da I Conferência Nacional de Políticas de Promoção da Igualdade Racial. Estado e sociedade promovendo igualdade racial. Disponível em: http://www.presidencia.gov.br/estrutura_presidencia/Seppir/publicacoes/. Acesso em: 25 dez. 2018.

Brasil, Presidência da República. Decreto ${ }^{\circ}$ 6.872, de 4 de junho de 2009. Aprova o Plano Nacional de Promoção da Igualdade Racial - PLANAPIR, e institui o seu Comitê de Articulação e Monitoramento. Disponível em: http://www.planalto.gov.br/ccivil_03/_Ato2007-2010/2009/Decreto/D6872.htm. Acesso em: 25 dez. 2018. 
Actors and their Influence on Policies by their Proposals from National Conferences

ABSTRACT Introduction: The paper assesses if and to what extent the different actors represented at policy conferences influence the outcome of decision-making, expressed in the approved proposals incorporated into the policy. It is assumed that the dynamic of interaction between governmental and non-governmental actors, as well as among non-governmental actors, impacts the power of influence of each actor in the respective policy. The hypothesis is that a more cooperative dynamic favors the reproduction of the actors' influence in the conference, while a more competitive interaction tends to affect that influence and balance it among the actors. Methods: We examine the influence of the actors from the proposals of their interest approved in six policy conferences: the 1st Conference on Aquaculture and Fisheries, on Cities, on Environment, the 1st Policy Conference on Sport, on Policies for Women and on Policies for the Promotion of Racial Equality. The paper compares the content of the approved proposals with the content of the policy programs formulated along the following years. By content, we mean the purpose, the intention of the proposal, and not the wording of the text in itself. By keywords identified in each proposal, they were classified (1) in incorporated or rejected and (2) according to the stakeholder. For doing so, the final document from each conference, as well as the government plans describing the programs of each policy, were analyzed. Results: From this analysis, the capacity of influence of each actor in the policy was assessed. The results show that the influence of each actor in a policy varies and is affected by the political dynamics of the area, as expected. Discussion: Although they are potentially inclusive spaces, conferences can generate results that are not representative of the actors represented in them, due to the way in which are combined their design and the political dynamics of the area.

KEYWORDS: conferences; proposals; actors; influence; policies.

This is an Open Access article distributed under the terms of the Creative Commons Attribution Non-Commercial License which permits unrestricted non-commercial use, distribution, and reproduction in any medium provided the original work is properly cited. 